\title{
Intellectual disability in South Africa: Addressing a crisis in mental health services
}

The recent focus on the Life Esidimeni tragedy in South Africa (SA) raises a number of key questions about mental health policies and practices in general in SA, and about policies and practices surrounding intellectual disability in particular. ${ }^{[1]}$ Has SA done enough in the area of mental health? What additional work is needed in psychiatry and mental health in general, and in the field of intellectual disability specifically?

In recent decades, rigorous data on the prevalence of mental disorders and on their associated burden have emerged from around the world, and from SA. ${ }^{[2,3]}$ This work has emphasised that there is a large treatment gap, particularly in low-resourced countries. Such data, together with an emphasis on the human rights of those living with mental disorders, has helped lead to the emergence of global mental health as a key discipline. ${ }^{[4]}$

A public mental health approach in SA has also led to a number of important advances. The Mental Health Act of 2002 $2^{[5]}$ emphasises human rights of patients. Consistent with the World Health Organization's Mental Health Action Plan, SA has developed a new Mental Health Policy Framework and Strategic Plan (2013 - 2020) that emphasises the value of a primary healthcare approach in reducing the treatment gap. ${ }^{[6]}$

However, ongoing challenges remain. Mental Health Review Boards, established by the Act, are functioning in only some parts of the country, and have not substantially contributed to increased resources for mental health services. ${ }^{[7]}$ Implementation of the mental health policy has not yet occurred, and the ideal of sufficient human resources to meet needs is far from achieved. ${ }^{[2]}$

The attention of mental health administrators in SA is typically focused on individuals with serious mental illness who require admission to acute psychosis units, partly because such patients can be very difficult to manage in the primary care units to which they are first admitted, according to the Act. Clinicians work hard to admit and discharge patients quickly, and to minimise readmissions in the absence of sufficient community resources. ${ }^{[8]}$

Far less attention is paid to common mental disorders. South African Stress and Health (SASH) survey data note the high economic costs of failing to provide appropriate interventions for such patients. ${ }^{[9]}$ But there is little pressure on policy makers to find the relevant funding. Consumer advocacy organisations have emerged, and are certainly attempting to draw attention to this issue.

Patients with intellectual disability are particularly at risk of being overlooked, and the Life Esidimeni tragedy is the proverbial canary in the coalmine, representing a crisis in mental health services. We have emphasised elsewhere that maladministration of such services can be and has been deadly. ${ }^{[1]}$ The Life Esidimeni tragedy points to systematic flaws in mental health service planning and implementation in SA.

What needs to be done?

First, we need to emphasise again that in terms of addressing the treatment gap, it is less expensive for the country to put good health systems in place than not to do so. Mental health is a key issue for sustainable development; return on investment in early diagnosis and intervention is not only high, but it is key if the Sustainable Development Goals (where mental health is now clearly emphasised) are to be met. ${ }^{[10]}$ In addition, we need to emphasise again the human rights of all patients, including those with mental disorders and with intellectual disability. All provincial departments of health need to ensure that Review Boards are constituted and functioning. Review Boards and civil society organisations need to flex their muscles more in order to secure increased resources for those living with mental disorders.

Second, an integrative and convergent approach to mental disorders in general, and intellectual disability in particular, is needed. ${ }^{[11]}$ Some have argued for the importance of primary care screening and management, others for the need for tertiary specialty services: both are needed. Some have emphasised the biomedical aspects of intellectual disability, others have emphasised the sociopolitical contributors to its neglect: both need to be addressed. Based on earlier research to develop norms for community mental health services in SA, ${ }^{[12]}$ the National Department of Health has recently issued a Government Gazette notice providing a licensing framework for non-governmental organisations (NGOs) in community mental healthcare. This needs to be implemented swiftly and with appropriate resources.

Third, we need leadership in the field of intellectual disability: ${ }^{[13]}$ key are champions who will introduce innovative services, conduct relevant research, provide policy guidance to government and advocate for the rights of some of the most neglected and vulnerable members of our society. These champions need to come from diverse sectors, including government, academia and NGOs. Courageous leadership is needed by health administrators; they must resist ongoing pressures to 'save money' by emphasising the cost-efficiency of treatment as well as the human rights of patients. Clinical-academic leadership is also crucial; medical specialists have not yet established intellectual disability as a specific, albeit cross-disciplinary, subspecialisation: this is a key step in order to promote services, teaching, and research, in primary through tertiary contexts. ${ }^{[14]}$

\section{Dan J Stein}

Department of Psychiatry and MRC Unit on Risk and Resilience in Mental Disorders, Faculty of Health Sciences, University of Cape Town and Groote Schuur Hospital, Cape Town, South Africa dan.stein@uct.ac.za

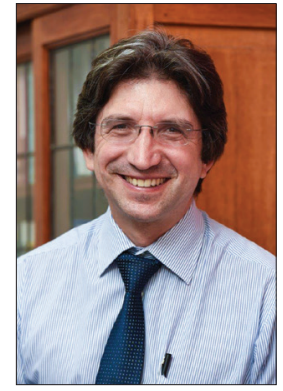

\section{Katherine Sordsdahl, Crick Lund} Alan J Flisher Centre for Public Mental Health, Division of Public Mental Health, Department of Psychiatry, Faculty of Health Sciences, University of Cape Town, South Africa
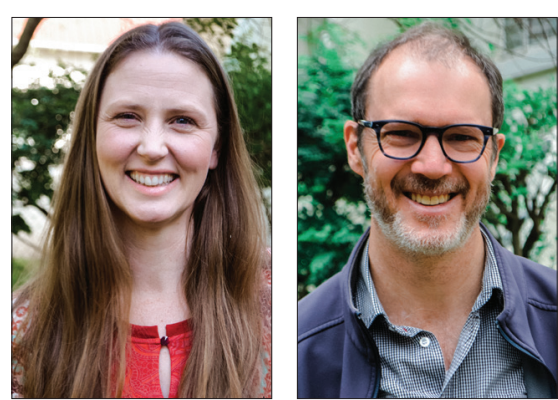
1. Stein DJ, Chambers C, Daniels I, et al. Death by maladministration: An important category of patient mortality. S Afr Med J 2017;107(4):280-280. https://doi.org/10.7196/SAMJ.2017.v107i4.12389

2. Sorsdahl K, Stein DJ, Lund C. Mental health services in South Africa: Scaling up and future directions. Afr J Psychiatry 2012;15(3):168-171. https://doi.org/10.4314/ajpsy.v15i3.21

3. Williams DR, Herman A, Stein DJ, et al. Twelve-month mental disorders in South Africa: Prevalence, service use and demographic correlates in the population-based South African Stress and Health Study. Psychol Med 2008;38(2):211-220. https://doi.org/10.1017/S0033291707001420

4. Prince M, Patel V, Saxena S, et al. No health without mental health. Lancet 2007;370(9590):859-877. https://doi.org/10.1016/S0140-6736(07)61238-0

5. South Africa. Mental Health Care Act No. 17 of 2002. http://www.gov.za/sites/www.gov.za/files/a17-02 pdf (accessed 9 February 2018).

6. National Department of Health, South Africa. National Mental Health Policy Framework and Strategic Plan 2013 - 2020. 2012. https://www.health-e.org.za/wp-content/uploads/2014/10/National-MentalHealth-Policy-Framework-and-Strategic-Plan-2013-2020.pdf (accessed 9 February 2018).

7. Lund C, Stein DJ, Flisher AJ, Mehtar S. Challenges faced by South African health services in

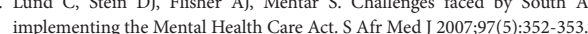

8. Lund C, Oosthuizen P, Flisher AJ, et al. Pathways to inpatient mental health care among people with 8. Lund C, Oosthuizen P, Flisher AJ, et al. Pathways to inpatient mental health care among people with
schizophrenia spectrum disorders in South Africa. Psychiatr Serv 2010;61(3):235-240. https://doi. schizophrenia spectrum diso
org/10.1176/ps.2010.61.3.235
9. Lund C, Myer L, Stein D, Williams D, Flisher A. Mental illness and lost income among adult South Africans. Soc Psychiatry Psychiatr Epidemiol 2013:48(5):845-851. https://doi arg/10.1007/s00127012-0587-5

10. Chisholm D, Sweeny K, Sheehan P, et al. Scaling up treatment of depression and anxiety: A global return on investment anlysis. Lancet Psychiatry 2016:3(5):425-424, https//doi 0rg/10.1016/S22150366(16)30024-4

1. Stein DJ. Philosophy of Psychopharmacology. Cambridge: Cambridge University Press, 2008.

12. Lund C, Flisher AJ. A model for community mental health services in South Africa. Trop Med Int Health 2009;14(9):1040-1047. https://doi.org/10.1111/j.1365-3156.2009.02332.x

13. Tomlinson M, Lund C. Why does mental health not get the attention it deserves? An application of the Shiffman and Smith framework. PLoS Med 2012;9(2):e1001178. https://doi.org/10.1371/journal.
thention the Shiffman an

14. Molteno C, Adnams C, Njenga F. Sub-specialties in psychiatry in Africa - intellectual disability. Afr J Psychiatry 2011;14(1):1,3.

S Afr Med J 2018;108(3):147-148. DOI:10.7196/SAMJ.2018.v108i3.13171 